\title{
Topic and Focus at the Peripheries: The Dynamics of Tree Growth
}

\author{
Ruth Kempson, Jieun Kiaer, Ronnie Cann \\ King's College London and Edinburgh \\ kempson/kiaerddcs.kcl.ac.uk, ronniedling.ed.ac.uk
}

\begin{abstract}
In this paper topic and focus effects at both left and right periphery are argued to be epiphenomena of general properties of tree growth. We incorporate Korean into this account as a prototypical verb-final language, and show how longand short-distance scrambling form part of this general picture. Multiple longdistance scrambling effects emerge as a consequence of the feeding relationship between different forms of structural underspecification. We also show how the array of effects at the right periphery, in both verb-final and other language-types, can also be explained with the same concepts of tree growth. In particular the Right Roof Constraint, a well-known but little understood constraint, is an immediate consequence of compositionality constraints as articulated in this system.
\end{abstract}

\section{Preliminaries}

In this paper, we take the structural concepts of Dynamic Syntax, together with the dynamics of tree growth which it articulates, sketch out how they can be used to characterise left and right periphery effects (see Cann et al 2004), and show how the explanations naturally extend to Korean, as a typical verb-fi nal language. In doing so, we show how focus and topic effects can be explained on an appropriately general cross-linguistic basis as due to general properties of tree growth. ${ }^{1}$

What the Dynamic Syntax model seeks to reflect is the step-wise way in which interpretation is built up during a parse sequence. It does so by defi ning a mapping from words, as parsing actions, onto progressively enriched representations of content, until a fi xed (in part, contextually established) interpretation is constructed. What is distinctive about this framework is its articulation of underspecifi cation and processes of update as intrinsic to the structural explanation of language. The growth process is taken as the basis of syntactic explanation, replacing all concepts of movement: a sentence is defi ned to be well-formed just in case there is at least one possible route through that process.

\footnotetext{
${ }^{1}$ This paper is an extension of ideas on topic and focus set out in Kempson et al 2004a, which was in its turn an extension of earlier work by Kempson and Cann in collaboration with Masayuki Otsuka and others. We are grateful to him for his contribution to that work, and to all those over recent years who have helped in the exploration of syntax through the dynamics of incremental processing. Particular thanks to Wilfried Meyer-Viol, without whom the formal framework could not have emerged in this form. Work for this paper was supported by the Leverhulme Trust's professorship to the fi rst author.
} 
Interpretation in this framework is articulated as a semantically transparent tree structure, in which a logical formula decorates the top node, and the various sub-terms of that formula decorate the nodes it dominates. Individual nodes are decorated either with Formula ( $F o$ ) and Type ( $T y$ ) values, or with requirements for such values. For example, decorations on nodes such as ?Ty $(t), ? T y(e)$, ?Ty $(e \rightarrow t)$ etc. express requirements to construct formulae of the appropriate type on the nodes so decorated, and these drive the subsequent tree-construction process. ${ }^{2}$ The process of satisfying such requirements forms the dynamic basis of the framework, while the formal system underpinning the partial trees that are constructed is a logic of fi nite trees (Blackburn and Meyer-Viol 1994). There are two basic modalities, $\langle\downarrow\rangle$ and $\langle\uparrow\rangle$, such that $\langle\downarrow\rangle \alpha$ holds at a node if $\alpha$ holds at its daughter, and its inverse, $\langle\uparrow\rangle \alpha$, holds at a node if $\alpha$ holds at its mother. Function and argument relations are distinguished by defi ning two types of daughter relation, $\left\langle\downarrow_{0}\right\rangle$ for argument daughters, $\left\langle\downarrow_{1}\right\rangle$ for functor daughters.

The process of both setting out and building up such an interpretation is defi ned as a serial process of tree growth following the order of words in a string. Individual steps take the parser from a single root-node of a tree, decorated with ?Ty $(t)$, indicative of the requirement (the assigned goal) of establishing a formula of type $t$, fi nally deriving a binary branching tree with all nodes decorated with formula values (Figure 1). There is always one node identifi ed as under development, indicated by the pointer, $\diamond)$ :

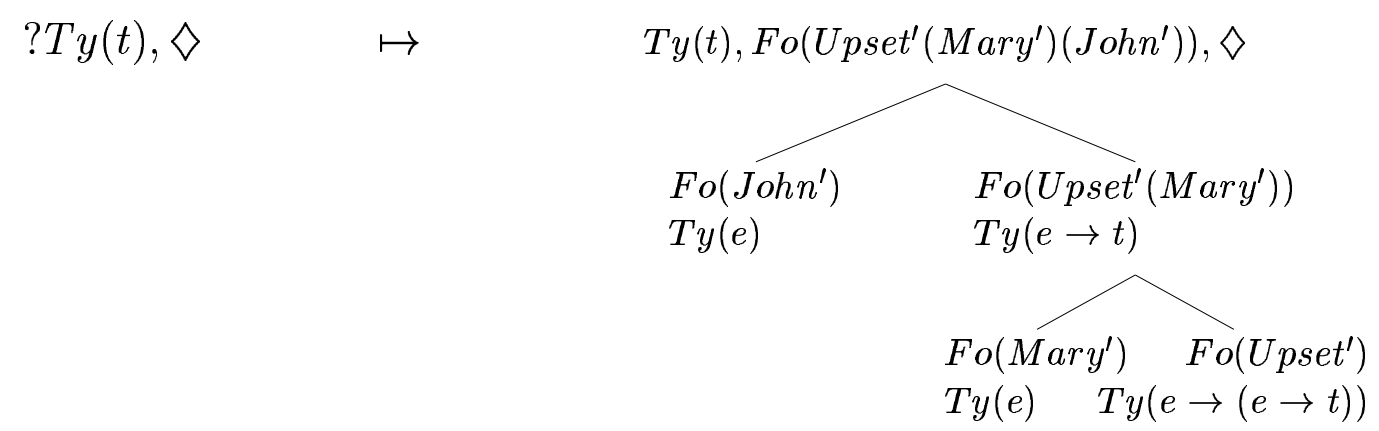

Initial Step Parsing actions

Final step

Figure 1: Parsing John upset Mary

These steps are determined either by general computational actions, such as anticipating a subject-predicate structure, or lexical actions triggered by lexical items. In both cases, these are defi ned as actions for updating a partial tree from

\footnotetext{
${ }^{2}$ All noun phrases are taken to project terms of type $e$. The logical language in terms of which these Formula values are expressed is the epsilon calculus, the language constituting the formal study of arbitrary names of predicate logic proofs. Accordingly all quantifi cation is expressed in terms of type $e$ terms, with all scope dependencies expressed within the restrictor of the individual terms. We leave this on one side in this paper. See Kempson et al 2001, and Kempson and Meyer-Viol 2004.
} 
the initial tree with but a single node to a tree whose top node is decorated with a propositional formula. There is cross-linguistic variation in the balance of computational and lexical actions. In some languages, e.g. English, the verb projects only predicate-internal structure. In others - the pro-drop languages the verb projects a propositional structure, with variation as to which of those arguments are pronominal-like in being decorated in a way that enables their identifi cation directly from the context.

Central to this account are concepts of structural and content underspecifi cation and their update, both expressed in terms of tree growth, with wellformedness defi ned as the availability of at least one derivation leading to a tree with no outstanding requirements, having used all the words in sequence. First, content underspecifi cation, the familiar case of context-dependence, involves lexical projection of a place-holding meta-variable to be replaced as part of the interpretation-construction process, such variables being projected by anaphoric and other expressions (eg. verbs with pro-drop properties, in decorating their argument nodes with such place-holding variables). Ty(e) metavariables take the form $F_{o}(\mathrm{U}), ? \exists x . F_{O}(x)$, the requirement indicating that the meta-variable $\mathrm{U}$ must be replaced with a specifi c formula value. As we shall see, anaphoric expressions differ according to whether these meta-variables are associated with a restriction that they decorate the terminal node in a tree, as do regular words, or not (in which case they are more like agreement devices). ${ }^{3}$ More controversially, the concept of underspecifi cation is extended to structure, with long-distance dependency effects expressed by the construction of a node in the logical structure which does not have a specifi ed, fi xed, position within the tree at the stage in the interpretation process at which it is introduced. A rule of *Adjunction introduces such an unfi xed node, which does not have a fi xed tree node address: it is marked as being dominated by the top node through the underspecifi ed modal relation, $\left\langle\uparrow_{*}\right\rangle \operatorname{Tn}(0)$, where $\operatorname{Tn}(0)$ is the tree node address of the top node. In other words, a node is introduced that is linked through an unspecifi ed sequence (possibly null) of mother relations to the top node and that needs, at some point in the construction process, to be fully specifi ed, thus fi xing the node in the structure. The fi xing of this node is thus resolved at some later point in the derivation, at the point in movement frameworks where a gap appears. Schematically, we represent this in Figure 2, which shows the result of parsing Mary, John upset: the dashed line indicates the unfi xed node and the dotted arrow indicates the process by which this is merged with the object-

\footnotetext{
${ }^{3}$ The restriction that the decoration must be on a node that remains terminal throughout the derivation is expressed as ? $\left[\downarrow_{0}\right] \perp$ - 'in all developments, any decorations on a daughter node yields falsity'.

${ }^{4}$ Formally, this characterisation of domination in terms of the Kleene star operator is standard in tree-theoretic grammars (see Rogers 1995), and is identical to functional uncertainty of LFG, but the DS characterisation is distinctive in incorporating the dynamics of the progressive updating of that specifi cation within an individual construction process from left to right.
} 
argument node. Note the requirement ? $\exists x . T n(x)$ which drives the merge process. The result of such a process, which unifi es the information on the unfi xed node with that on the object node, yields a fi nal tree identical to that obtained from parsing John upset Mary.

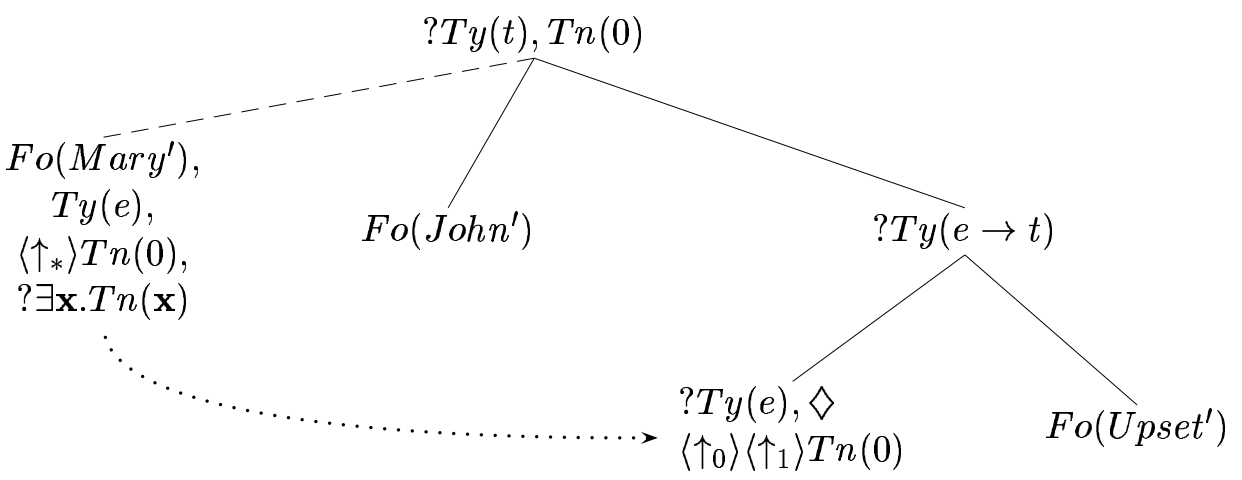

Structural position update

Figure 2: Parsing Mary, John upset.

This introduction and subsequent updating of unfi xed nodes can be further constrained. In rich case-marking languages such as Greek, Korean, etc., the range of positions which such an initially unfi xed node can ultimately inhabit within the resulting confi guration may be narrowed down by the case specifi cation. Accusative case may be defi ned as a requirement for a predicate node as mother, in the form ? $\left\langle\uparrow_{0}\right\rangle T y(e \rightarrow t)$, and nominative as a requirement of the form ? $\left\langle\uparrow_{0}\right\rangle T y(t)$. In Greek, for example, the case serves to ensure that a node decorated at the left periphery by an accusative-marked NP can only merge with a node which in the result will turn out to be immediately dominated by a node of $T y(e \rightarrow t)$ :

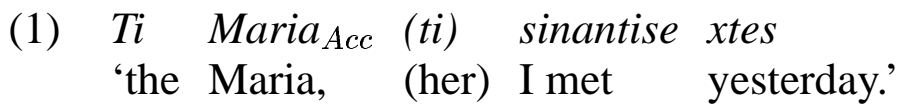

[Greek]

In such a language, since the two nodes can be merged anyway, we would expect such pronouns to be optional. Case may, however, play a more constructive role. For example, in verb fi nal languages, with their free local NP-ordering within a clause, case specifi cations may induce the construction of the requisite tree relation: ${ }^{5}$

\footnotetext{
${ }^{5}$ The word order variation in local scrambling is reported to involve no difference in propositional meaning. See Büring 1997, Hoffman 1995.
} 
(2) Jina-ka sakwa-rul mek-ess-ta

Jina $_{N O M}$ apple $_{A C C}$ eat $P A S T, D E C L$ [Korean]

'Jina ate an apple.'

(3) sakwa-rul Jina-ka mek-ess-ta

apple $_{A C C}$ Jina $_{N O M}$ eat $P A S T, D E C L$

'Jina ate an apple.'

The process is one of building an unfi xed node, decorating it, fi xing its relation to the local type- $t$-requiring node, and then repeating this sequence of actions as many times as necessary. We display the process schematically for (3) in Figures 3-5. In Figure 3, we begin with an unfi xed node which permits the parse of the accusative NP. This is then updated, fi xing the position of this node as the internal object. ${ }^{6}$ Figure 4 shows the process of parsing the subject, Jina$k a$, while the actions defi ned by the lexical specifi cation of the verb project a full template of structure, collapsing its argument nodes with any non-distinct unfi xed nodes; and the formula decorations on the nodes then duly combine to form the tree in Figure 5 to yield the resulting logical formula:

$$
\text { Fo }\left(\operatorname{Mek}^{\prime}\left(\epsilon, x, \operatorname{Sakwa}^{\prime}(x)\right)\left(\operatorname{Jina}^{\prime}\right)\right), T y(t)
$$

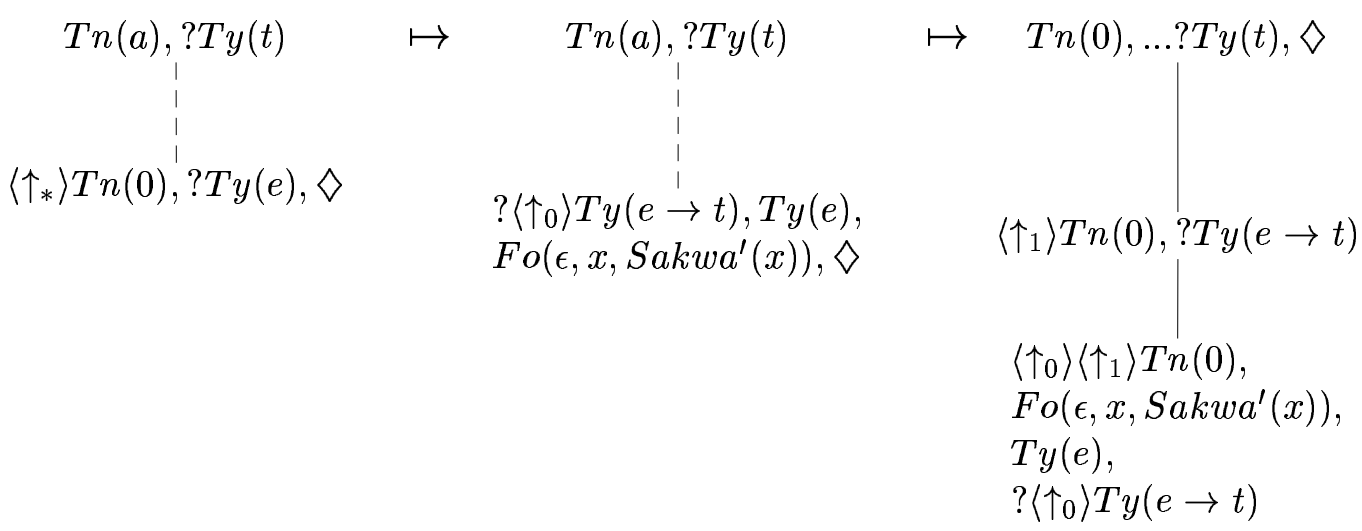

*Adjunction

sakwa-rul

Fixing the position

Figure 3: Parsing sakwa-rul in (3)

It is thus the successive application of $*$ Adjunction plus immediate updating of such unfi xed nodes that underpins the free ordering of NPs within a clause?

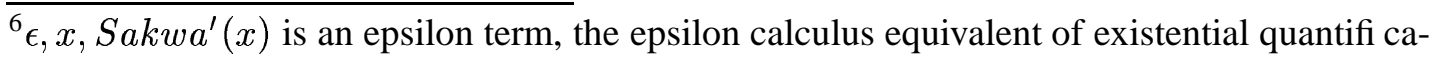
tion, here ranging over apples.

${ }^{7}$ Such local scrambling is associated with fi xed scope effects, at least when an indefi nite NP precedes a nonindefi nite NP. We do not take up scope effects in this paper, but see Kempson and Meyer-Viol 2004 for a discussion of the extent to which these follow linear order, and explanation of cases which diverge from this.
} 


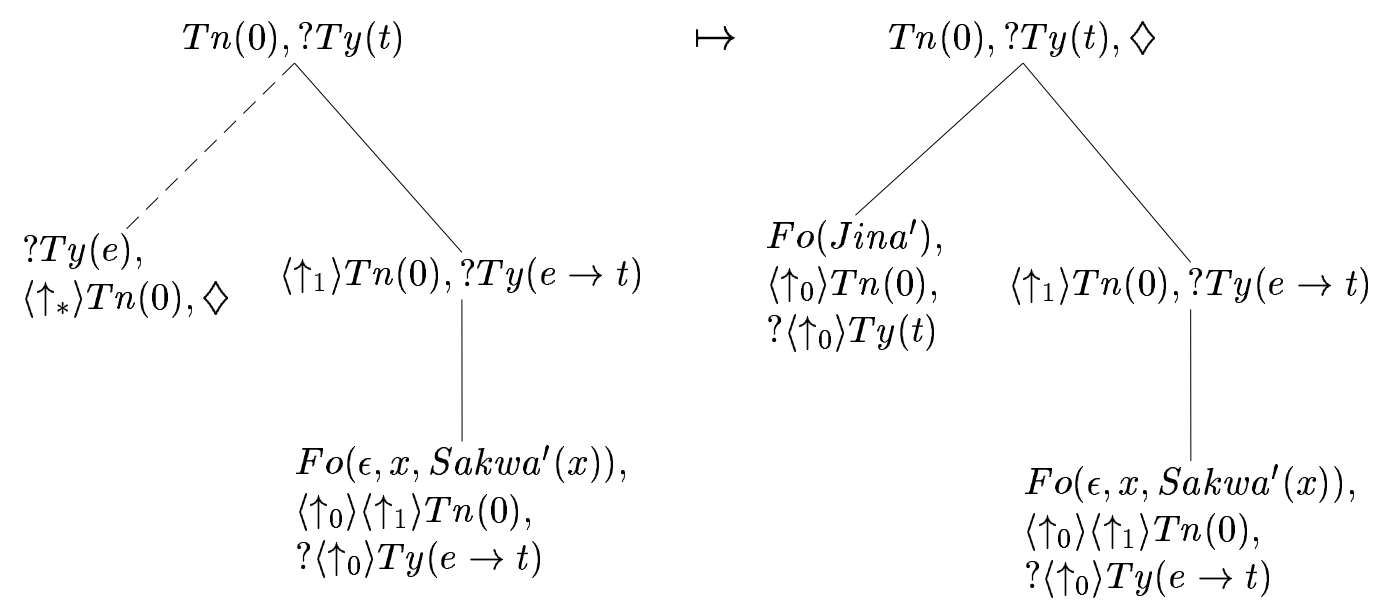

Figure 4: Parsing Sakwa-rul Jina-ka in (3)

Notice how the resulting structure is identical to the structure derived from the English parsing actions, commensurate with the view that structures underpinning natural language are universal, differences between languages residing in the varying computational/lexical actions that yield such logical-form structures as output.

This successive enrichment of each node - introduced fi rst as unfi xed, but then fi xed immediately subsequently by the case specifi cation - is essential as a means of inducing structure over a sequence of noun phrases when the verb follows them all, as there will be no template of structure provided by the verb; and the DS system imposes the restriction that only one type of unfi xed tree relation be introduced from a given node at a time. This is because introduction of any tree relation, even if only partially determined, must preserve unique identifi ability of node relations in partial trees. Formally, there is no restriction to this effect, apparently allowing the introduction of more than one unfi xed node, but since, with no fi xed structure, the introduction of a second relatively weakly specifi ed tree relation won't be distinct from the already introduced unfi xed node, the two nodes will always collapse with each other to yield a nondistinct result, generally leading to inconsistency. ${ }^{8}$ This restriction forces us to presume that case has this constructive function wherever more than one such node appears to be introduced, in order to ensure the enrichment of the fi rst introduced unfi xed node before the second unfi xed node is introduced; and so on. It also forces us to posit distinct processes introducing unfi xed nodes subject to different locality constraints on the domain within which that unfi xed node needs to be resolved (parallelling resolution of anaphoric expressions), since long and short scrambling effects can co-occur, as we shall shortly see.

${ }^{8}$ Thanks to Wilfried Meyer-Viol for extensive discussions persuading us of this. 


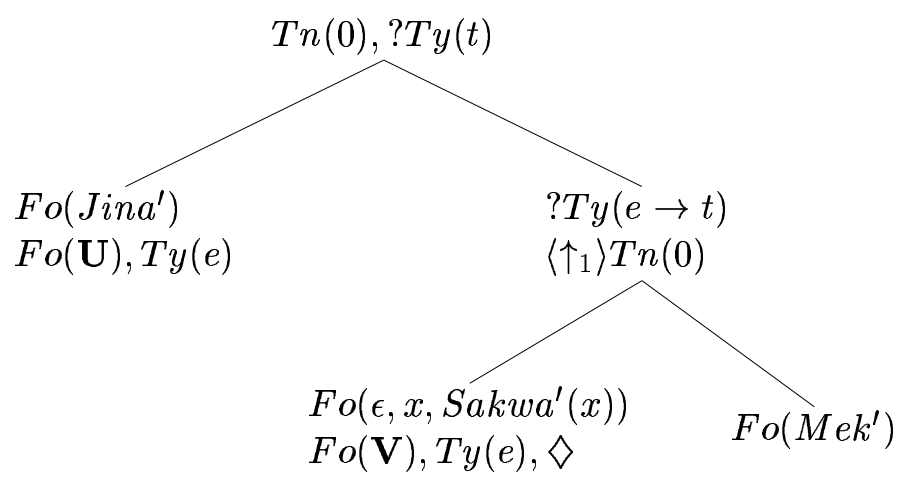

Figure 5: Parsing Sakwa-rul Jina-ka mek-essta in (3)

So we defi ne:

(i) a process of introducing an unfi xed node which has to be locally resolved within a single predicate-argument array (Local*Adjunction);

(ii) a process of constructing an unfi xed node which has to be resolved within an individual tree but not necessarily locally (*Adjunction); and

(iii) a process constructing a node without any constraint on the fi xing of its relation to other nodes in the tree other than having to be determined within the overall construction process (Generalised Adjunction).

Of these, it is the first two that play an essential role in this paper, with $L o$ cal*Adjunction operative in short scrambling, as we have just seen. ${ }^{9} *$ Adjunction is the process already introduced in connection with English, which we return to in discussing long-distance scrambling. The use of this range of strategies for licensing the introduction of unfi xed nodes, with its natural parallelism with constraints on anaphora, provides a notable advantage in addressing verbfi nal languages, since the assumption that at some level all languages project the same structural confi guration can be preserved without having to postulate the extensive scrambling processes needed to sustain such a claim in other frameworks (Kayne 1994; Simpson and Bhattachariya 2003).

Like all other rules, this process of introducing unfi xed nodes that are subject to a locality constraint may vary across languages as to whether the process is available as the general computational action of Local*Adjunction, as in Korean and Japanese, or as a lexical action, providing fi rst confi rmation of this as a distinct process. In the Romance languages and Greek, this process is arguably

${ }^{9}$ This is differentiated from *Adjunction by the additional constraint of the form $?\left\langle\uparrow_{0}\right\rangle\left\langle\uparrow_{*} *\right.$ \rangle $\operatorname{Tn}(a)$ determining that the node in question can only be resolved at an argument node within an individual predicate-argument structure. See Kempson et al 2001 for justifi cation of this characterisation of locality. 
restricted to lexical action, being the basis for the pre-verbal position of clitics in fi nite clauses:

$$
\begin{aligned}
& \text { Jean le lui } \quad \text { a donné } \\
& \text { Jean it } \text { him }_{D A T} \text { has given } \\
& \text { 'Jean gave it to him.' }
\end{aligned}
$$

\subsection{Building Linked Trees}

The process of inducing semantic structures in tree format is extended to the construction of paired trees by the incorporation of a LINK relation between trees. An additional modal operator, $\langle L\rangle$, and its inverse $\left\langle L^{-1}\right\rangle$, are used to defi ne transitions from an arbitrary node in one tree to the top node of a new tree, with a requirement on this new tree that it must involve development so that one of its nodes shares a term with the node (the 'head') from which the transition was constructed. Such a device is used to analyse relative clauses - notice the interpretation of who as picking out the same individual as that assigned to John:

John, who Sue upset, cried.

The action of introducing such paired trees is a general computational action which projects, from a node decorated by some term, $\alpha$, a linked tree (indicated in Figure 6 by the modality $\left\langle L^{-1}\right\rangle$ ) which is required to contain a copy of $\alpha$. Again, we use the Kleene operator, but this time in combination with the concept of requirement. A decoration, ? $\left\langle\downarrow_{*}\right\rangle F_{O}\left(J o h n^{\prime}\right)$ is thus a requirement that somewhere in the tree as it develops there must be a node decorated with Fo $\left(J o h n^{\prime}\right)$. It is this requirement which determines the shared term in the output semantic representation of this paired, so-called linked tree, for no output will be wellformed unless such a requirement is met. As Figure 6 illustrates, the fi rst partial tree contains a binary branching structure made up of what is to be construed as the head of the relative plus a twinned predicate-requiring node. The second, linked, tree is introduced by a $L I N K$ transition from this subject node, and this newly introduced tree has a requirement for an occurrence in that tree of the term $F_{o}\left(J_{o h n}\right)$. Parsing the relative pronoun who provides the required copy of this term at an unfi xed node, hence the position of such expressions at the left periphery of the relative clause.

Then, in subsequently following the parse, the unfi xed node that the relative pronoun has decorated will get unifi ed with the node denoting the object of upset, just as in the simple case of Figure 5. The adjunct 'linked' tree is then completed, and, with $F o\left(U p s e t^{\prime}\left(J o h n^{\prime}\right)\left(S u e^{\prime}\right)\right)$ decorating the top node of that adjunct tree, the pointer will return to the primary structure and the parse proceed to the predicate, where parsing cried will lead to the addition of 

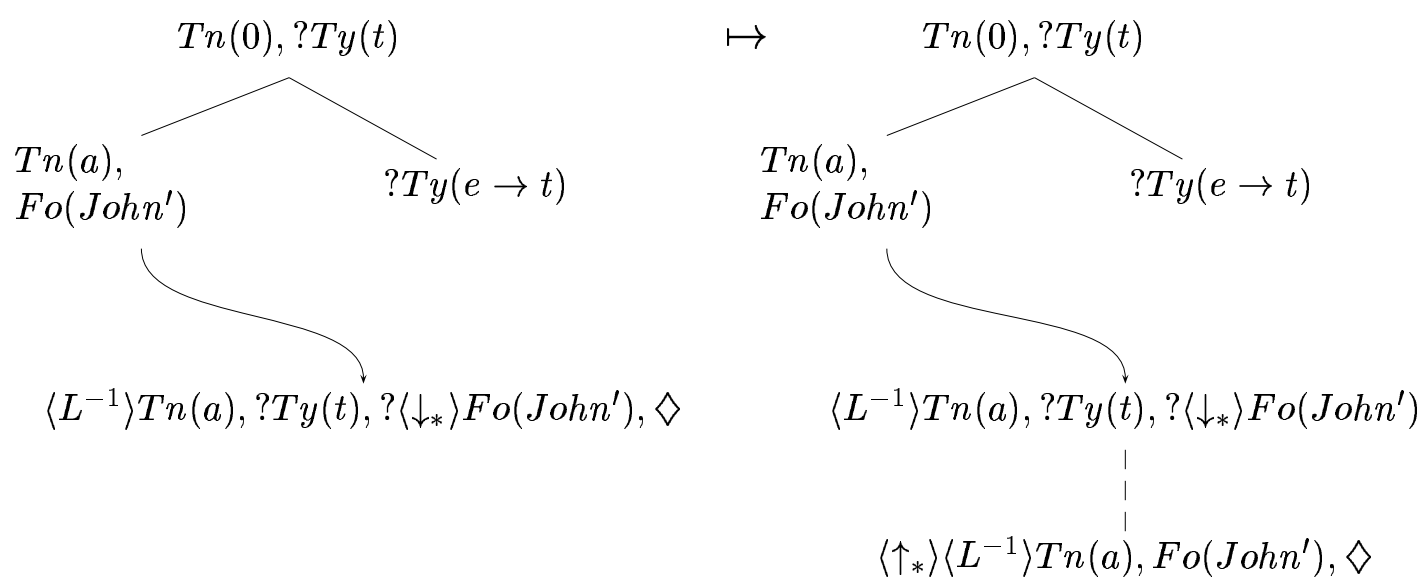

Figure 6: Parsing John, who...

the predicate formula $F_{o}\left(C r y^{\prime}\right)$ (we ignore tense in this paper), and the overall result will duly be a conjunction of formulae derived from the primary and linked structures: $F o\left(\operatorname{Upset}^{\prime}\left(\operatorname{John}^{\prime}\right)\left(\operatorname{Sue}^{\prime}\right) \wedge \operatorname{Cry}^{\prime}\left(\mathrm{John}^{\prime}\right)\right){ }^{10}$

Two things should be noted about the decorations on such trees, and the words that give rise to them. First, lexical items do not decorate trees themselves, nor is the structure defi nable over the string. The items that decorate the nodes of the tree are sub-terms of the logical-form language. This is most obviously true of the anaphoric expressions her and who, but is a general property. Words are defi ned as procedural devices that provide the actions that lead to tree-decorations. Secondly, decorations on the resulting tree show no reflex of the linear order of the words that led to such a tree. The hierarchical confi guration given by an individual tree reflects solely the mode of combination which leads to a resulting interpretation. As a mapping from string onto semantically transparent tree structure, this might seem a notational variant of much more standard accounts of left-periphery accounts in terms of the two-fold distinction between base-generation (involving essential anaphoric co-indexing) and generation by movement. But, as we shall see, the possibility of structures with characteristics partly redolent of movement, partly of base generation, will emerge here unproblematically as mixed effects that arise through the feeding relations between anaphora and tree growth process, as an interpretation is progressively built up.

\footnotetext{
${ }^{10}$ See Kempson 2003 for justifi cation of this account of nonrestrictive relatives. See Kempson et al 2001 for justifi cation of this as an account of relative clause construal in general.
} 


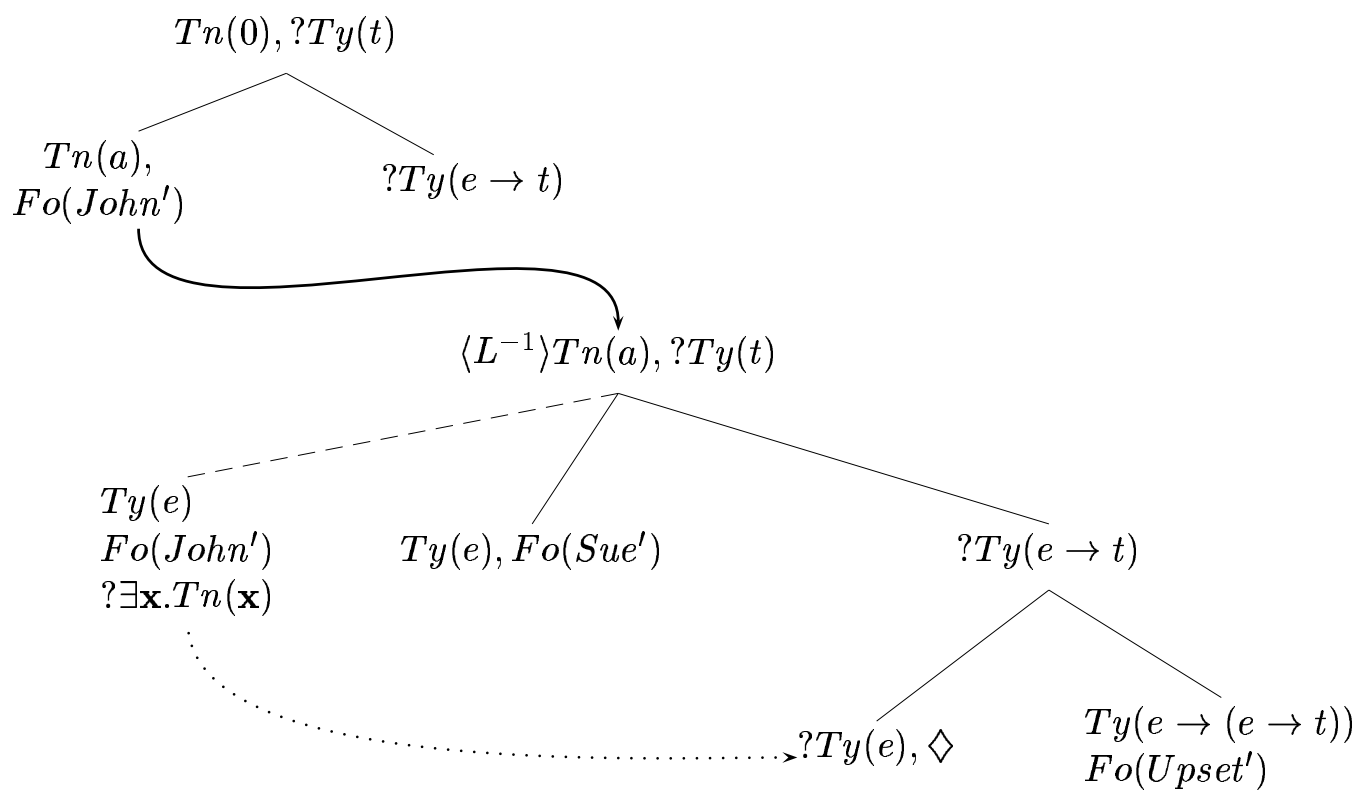

Figure 7: Parsing John, who Sue upset, ...

\subsection{Building Linked Structures at the Outset}

With these tools in mind, we can now see what applicability the concepts of linked structures and unfi xed nodes have to the characterisation of left-periphery effects. One strategy for interpreting left-peripheral expressions as in John, I like him uses the same concept of paired linked structures used in relative clause construal, but this time without any analogue of a relative pronoun, so an anaphoric relation has to be established. Nothing in the concept of paired linked trees precludes the possibility of one such tree being a tree with top node of type $e$, so that a LINK transition is defi ned from that node, as decorated by the left-peripheral expression: ${ }^{11}$

$$
\langle L\rangle T n(0), F_{0} o(\alpha), T y(e) \quad T n(0), ? T y(t), ?\langle D\rangle F o(\alpha)
$$

Though, at fi rst sight, it isn't obvious that this is a display of two trees, it is: both trees at the particular stage of development displayed contain but a single node. The bonus of having analysed relative clause construal in terms of a constructed LINK transition across trees, in so doing imposing an anaphoric connectedness, is that it immediately carries over to these structures, imposing equally the requirement of anaphoric relatedness. And here, with no analogue to a relative pronoun, we expect the obligatory occurrence of a pronoun. In the particular format of ? $\langle D\rangle F_{o}(\alpha)$, there is effectively no locality restric-

$\overline{{ }^{11} D \text { is an operator ranging over LINK }}$ or daughter relations. 
tion on this anaphoric relatedness, since the copy required can occur at any node of any subsequently introduced structure. Nevertheless, the modal requirement has some force. Given the association of satisfying all requirements with wellformedness, all successful derivations must involve the construction of a copy of the term decorating $F_{O}\left(J o h n^{\prime}\right)$ and, with no analogue to a relative pronoun to provide such a copy by lexical stipulation, this requirement can only be met through suitable construal of the anaphoric expression. Notably no item-specifi c characterisation of the pronoun is needed to reflect this obligatory co-dependency of pronoun and left-peripheral expression. This strategy corresponds to Hanging Topic Left Dislocation (HTLD: Anagnostopoulou 1997), and is displayed by Greek mismatching case effects: ${ }^{12}$

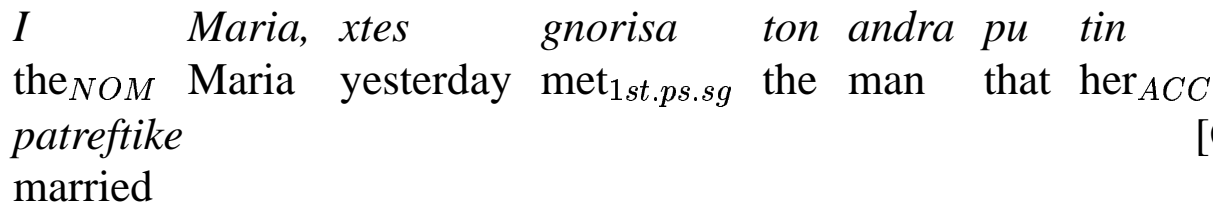

[Greek]

'Mary, yesterday I met the man that married her.'

As we would expect in such an environment, there should be no case specifi cation providing instructions on decorating the linked structure, as that node will not become a substructure within the primary structure: the two trees remain as independent structures in the output, suitably anaphorically linked.

The form of the requirement imposed in this LINK transition suggests an immediate basis for variation. Given that it is expressed in terms of a modal requirement, we can defi ne natural variants by varying the modal operator. For example, we can vary the domain within which the copy is to be provided to that involving the $\left\langle\downarrow_{*}\right\rangle$ relation, which means that the copy is required to occur within an individual tree. With this variation, we have a paired structure with essential anaphoric connectivity but whose requirement matches the constraint imposed by introducing an unfi xed node whose position has to be resolved within an individual tree. This constraint appears to be operative in Korean, and also in Romanian: ${ }^{13}$

(7) ?? Sakwa-nun Jina-ka mek-un haksayng-ul a-n-ta. apple $_{T O P}$ Jina $_{N O M}$ eat $_{R E L}$ student $_{A C C}$ know $_{P R E S, D E C}$ 'As for an apple, Jina knows the student who ate.'

[Korean]

\footnotetext{
${ }^{12}$ Nominative case in Greek is expressed as morphologically null differentiation of the determiner.

${ }^{13}$ Romanian has two forms: one analogous to as for in English, which isn't subject to any such island sensitivity, and one, the simpler form as here, which is.
} 
(8) *Pe Ion n-am întîlnitfata care l-a văzut

As-for John not-I-have met the girl which him-has seen

anul trecut.

the-year last.

[Romanian]

'As for John, I have not met the girl who saw him last year.'

So we get the first blurring of the anaphoric and structural forms of update, a tightening of the locality constraint that yields Clitic Left Dislocation effects in head-initial languages (CLLD: Cinque 1990), with its intermediate status, in having some characteristics diagnostic of movement. Despite the varying stringency in the way such requirements have to be met, all share one property: the presented term which constitutes the point of departure for the LINK transition acts as a context relative to which the subsequent emergence of structure is defi ned. All such developments display a term that is shared with the structure which forms the starting sequence of the actions building a linked structure. Such an analysis, accordingly, reflects the way in which, in both HTLD and CLLD structures, the fi rst expression is construed as providing a context.

\subsection{Building Unfixed Nodes at the Outset}

The building of linked structures is by no means the only analysis available for left-peripheral expressions. To the contrary, the building of an unfi xed node within an individual tree provides another strategy. In applying this alternative strategy, we get the inverse of the HTLD and CLLD effects, the fi rst expression projected as providing some isolated term, which is to provide an update to what is projected immediately subsequently. This process, by defi nition, doesn't require pairing with a lexical pronoun. However, such a strategy may yet be possible in the presence of a pronoun within the primary structure, as in the Greek clitic-doubling sequences, already exemplifi ed in (1) and analysed in Figure 8. ${ }^{14}$ It is of interest in this connection to note the preverbal position of the clitic pronoun, a reflex of its having been introduced as decorating a locally unfi xed node, which is then updated - just as set out earlier for Korean. Notice that this introduction of an unfi xed node for the clitic to decorate is not precluded by the presence of the unfi xed node decorated by Ti Maria, since *Adjunction and Local*Adjunction are distinct rules associated with distinct, even if unfi xed, tree relations.

There is an immediate consequence to proposing any such analysis which is important in setting out bases for cross-linguistic variation. As Figure 8 shows, any pronominal expression which serves to identify the node with which the unfi xed node is to unify must decorate a non-terminal node in the tree: this puts

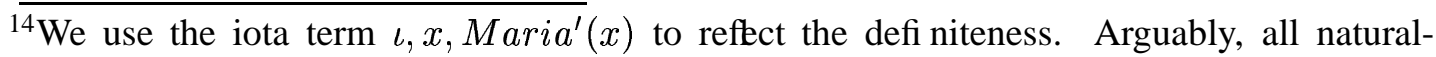
language names project this type of structure, Greek reffecting this in its morphology. In general, however, we suppress this level of detail.
} 


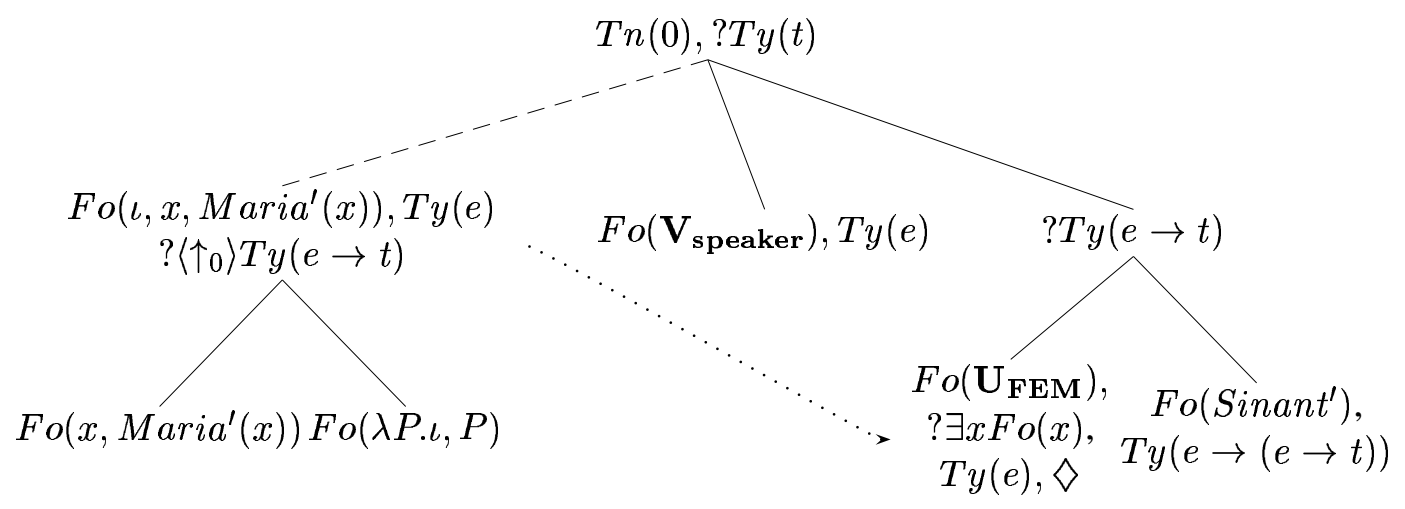

Figure 8: Parsing (1)

it in a category unlike other lexical expressions - one basic criterion of wordhood has got lost. This is a source of variation not only between individual languages, but also between individual pronouns within a single language. It notably matches the distinctiveness of dative clitic doubling in Spanish, which, unlike all other clitic doubling constructions, is not subject to any specifi city restriction - all NPs, quantifi ed or not, can occur with clitic doubling (see Kempson et al 2004 for further discussion):

(9) A familias de pocos medios (les) ofrecieron queso y leche to families of small means to them offer $_{3 p l}$ cheese and milk

'To low-income families, they offered cheese and milk .'

There is a further phenomenon that this analysis would lead us to expect. Since we are taking this terminal-node restriction to be defi nitive of a word's contribution to compositionality defi ned on the semantic tree, we would not expect the argument nodes which a verb may induce themselves to be subject to any such terminal-node restriction. And, accordingly, we expect that there will be two different forms of interpretation for subject position in all pro-drop languages, hence in Spanish and Korean alike. This is because the argument node the verb decorates may have its value determined in one of two ways. Either the value of the meta-variable at the argument node may be provided by building a linked structure, taking the term projected from the subject expression to decorate the introduced linked-structure node, and then using it to provide the context for identifying the value of this meta-variable by a process of substitution. Or the value of the meta-variable may be provided by taking the subject expression to provide decorations on an unfi xed node, unifying this unfi xed node with the subject node provided by the verb. And indeed, as is widely observed of such languages, both subject pro-drop and full pro-drop, the subject 
expression can either function to serve a focus effect, or more neutrally. ${ }^{15}$

Notice, more generally, what these two strategies immediately provide. We have one anaphorically-based strategy for building paired trees, over which a range of locality restrictions can be defi ned. And we have a strategy using the building of an unfi xed node within a single tree, into which pronouns of a certain category can provide input. There is no problem in positing two such alternative strategies, as the parsing perspective allows a number of alternative ways of constructing a given semantic representation. There is yet a further bonus to be gleaned from this account. These alternatives provide the means of reflecting a number of intervening structures. As we have already seen, on the one hand, the building of linked structures may be associated with a locality restriction more stringent than the mere pairing of anaphorically linked structures, despite being realised by an antecedent-anaphoric pairing. On the other hand, the building of an unfi xed node may be associated with unifi cation of a node decorated by a pronoun if that pronoun can be seen to have lost the full lexical status normally associated with words. As we shall see when we approach the right periphery, this corresponds directly to expletive pronouns, an account which in this framework we expect to be applicable not merely when pronouns precede the expression which provides their value. In the meantime, the availability of effects apparently intermediate between anaphoric and regular long-distance dependency is unproblematic here. ${ }^{16}$ This is distinct from movement accounts, for which such mixed effects, apparently blurring the dichotomy between movement and base-generation, is problematic. It is notable that in some recent analyses, the absolute nature of this dichotomy is weakened (Boeckx 2003).

\subsection{Multiple Scrambling at the Left Periphery}

Before turning to the right periphery, a novel advantage emerges from having distinguished the two processes *Adjunction and Local*Adjunction, with both processes introducing an unfi xed node from a node requiring type $t$. We can expect the one rule to feed the other, if we just defi ne *Adjunction as creating an unfi xed node which itself bears the requirement ?Ty $(t) .{ }^{17}$ This assumption

\footnotetext{
${ }^{15}$ See Belletti 1999 for arguments for the clause-external status of preposed subjects in Spanish, Jang 1998 for Korean, Kitagawa 1986 for Japanese.

${ }^{16}$ Given the omission of discussion of quantifi cation in this paper, we have to leave on one side any detailed account of specifi city effects, which are characteristic of clitic-doubled constructions. It should, however, be pointed out that by characterising indefi nites as epsilon terms, we expect them, and only them, to be licensed to decorate independent linked structures that require anaphoric copying, since, in virtue of their existential force, they allow indefi nite extendability of their scope. This corresponds to the observed restriction of Hanging Topic Left Dislocation Structures to referential expressions, with indefi nite expressions having to be construed as specifi c.

${ }^{17}$ No such freedom can be attributed to Local*Adjunction as it is defi ned to ensure essentially local projection of structure from any individual verb.
} 
immediately yields the multiple long-distance scrambling effects observed in verb-fi nal languages. For example, in Korean, there are examples such as (10), which can have either an object long-scrambled reading or an object-subject pair long-scrambled reading: ${ }^{18}$

\section{(10) Sakwa-rul Mina-ka Jina-ka mekessta-ko malhayss-ta apple $_{A C C}$ Mina $_{N O M}$ Jina $_{N O M}$ ate $_{C O M P} \quad \operatorname{said}_{D E C L}$ 'An apple, Mina said that Jina ate.' [only object sakwa scrambled] 'Jina said that Mina ate an apple.' [object-subject pair scrambled]}

Phonological information buttresses the assumption of constituency break that has to be constructed upon this analysis, making the requisite strategy defi nitively salient. For example, when there is an intonational break between sakwarul and Mina-ka, two lexical elements cannot be interpreted as one constituent or one pair. Yet, when there is a break between the fi rst subject Min-ka and the second subject Jina-ka, the object sakwa-rul and Mina-ka forms a constituent and yields a pair-wise reading. Previous approaches to these constructions have somehow to motivate these so-called 'surprising constituents', and this is done by invoking such constructs as vacuous verb-raising, oblique movement, etc. (see Koizumi 2000; Takano 2002). Yet, the motivation for such processes independent of these particular structures is not clear. In LFG (Lexical Functional Grammar), a constituent-forming operation is argued for (Nordlinger 1998) on the basis of one particular morpheme in the case-stacking language of Wambaya. A morpheme which has the function of forming a constituent from multiple elements is subject to the stipulated restriction that all such elements are semantically associated with each other at $f$-structure. ${ }^{19}$ However, on such an LFG account, restricted construal of dative NPs in multiple longdistance scrambling cannot be explained properly, because of the lack of any morphological indicator to trigger the requisite process. Notice how any such sequence of left-peripheral constituents that are to be interpreted as in some sense separated from their construal site MUST be interpreted as a constituent. Compared to (12), (11) is not well formed, because the left-dislocated dative NP is not interpretable as an argument of the verb mek-'eat' together with the following scrambled pair of object sakwa-rul and subject Mina-ka:

$$
\begin{aligned}
& \text { (11) * Yuna-ekey sakwa-rul Mina-ka Jina-ka mekessta-ko malhayssta-ko } \\
& \text { Yuna }_{D A T} \text { apple }_{A C C} \text { Mina }_{N O M} \text { Jina }_{N O M} \text { ate }_{C O M P} \text { said } \\
& \text { sayngakhayss-ta } \\
& \text { saynght }_{D E C} \\
& \text { * 'Jina thought that she said to Yuna that Mina ate an apple.' }
\end{aligned}
$$

\footnotetext{
${ }^{18}$ Such surprising constituents are also observed at the left periphery in German, to which we would expect the same arguments to apply.

${ }^{19} \mathrm{C}$-structure models the surface syntactic form of language, whereas $f$-structure models grammatical functions and other syntactic relations.
} 
(12) Yuna-ekey sakwa-rul Mina-ka Jina-ka cwuessta-ko Yuna $_{D A T}$ apple $_{A C C}$ Mina $_{N O M}$ Jina $_{N O M}$ gave $_{C O M P}$ malhayssta-ko saynggakhayss-ta said $_{C O M P} \quad$ thought $_{D E C}$

'Mina thought that she said that Jina gave an apple to Yuna.' 'Jina thought that she said that Mina gave an apple to Yuna.'

Such a constraint is hard to capture in LFG, as functional unification is only a two-step process and cannot reflect left-right parsing processes step by step. ${ }^{20} 21$

On the Dynamic Syntax account, such multiple long-distance scrambling effects follow directly. While the framework disallows the construction of more than one unfi xed tree node relation in any partial tree, *Adjunction can nevertheless feed Local*Adjunction. This has the effect of introducing an intervening node requiring ?Ty $(t)$, and this introduced node then allows the successive projection of a number of locally unfi xed nodes, each updated to a fi xed local relation. The result is an incomplete structure decorating an unfi xed node, itself to be updated later in the parse, which may be indefi nitely far away in the emergent tree. This leads us to expect that such apparent instances of multiple long-distance scrambling are obligatorily interpreted as local to one another. In Korean, within any one sentence, it may be that only one expression is interpreted as long-distant dependent from its source position as long as these form a constituent. But it may also be that two, or indeed more, expressions can be interpreted as long-distant dependent from their source position. Yet, all such cases must be construed locally within the same propositional structure:

(13) Sakwa-rul Mina-ka Jina-ka mekessta-ko malhayssta
apple $_{A C C}$ Mina $_{N O M}$ Jina $_{N O M}$ ate $_{C O M P}$ said
'The apple, Mina said that Jina ate.'
'Jina said that Mina ate an apple.'

The two forms of construal for (13) are displayed in Figures 9 and 10. The fi rst is the regular long-distance dependency using the construction and decoration of an unfi xed node of type $e$ unifying subsequently with the subordinate object node. $^{22}$ The second is the use of a step of *Adjunction followed by two steps

\footnotetext{
${ }^{20} \mathrm{We}$ are grateful to Mary Dalrymple and Devyani Sharma for discussing this problem with the second author, and for pointing out to us the problem these data pose for LFG.

${ }^{21}$ Of current orthodoxies, categorial grammar accounts (Steedman 2000) are best suited to expressing these data given indefi nitely fexible type assignment, but like LFG there is a commitment to symmetry between distributions at the left and right periphery, and any departures from this are problematic.

${ }^{22}$ One property of this tree which is unexplained here is the relation of the embedded propositional structure to the root, here specifi ed as a fi xed relation of immediate subordination. The introduction of the subordinate proposition-requiring node (to be developed by the actions of mekessta 'ate') is as a radically unfi xed node (possibly even part of a linked structure for a relative clause). The step of interpreting this very weak relation as immediate subordination is one of structural enrichment, analogous to the formula enrichment involved in anaphora construal (see Kempson submitted; Kempson et al 2004).
} 
of Local*Adjunction, each node so introduced getting immediately fi xed by the actions induced by the case specifi cation of the noun phrase. It is then the incomplete $T y(t)$-requiring node (with the structure it dominates) which unifi es with the subordinate node developed by the actions of mek- 'eat', in so doing, providing the object and indirect object values.

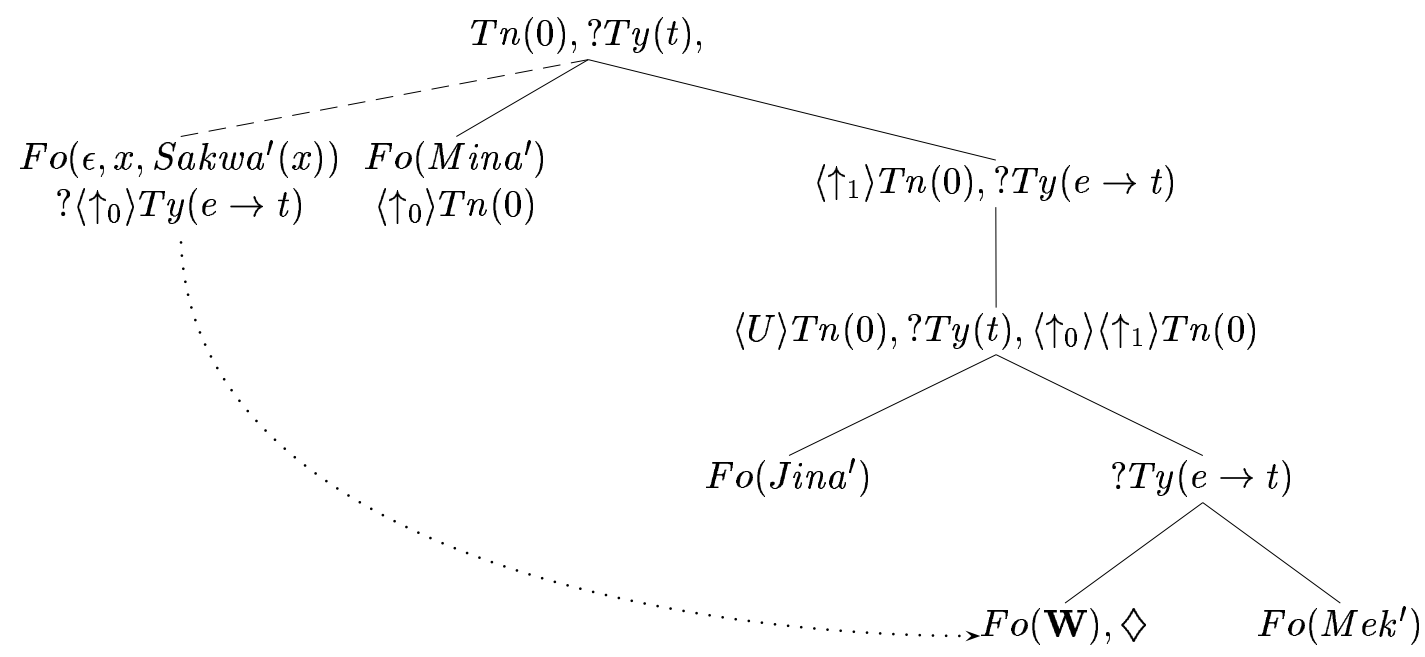

Figure 9: Left dislocation of sakwa-rul

In a framework in which concepts of structural underspecification are central, such multiple long-distance scrambling effects, with their particular incomplete-structure formation, are no more surprising than the phenomenon of long-distance dependency itself. In other frameworks, to the contrary, there is no reason a priori to expect that some sequence of argument expressions should function as a constituent, and some device has to be made available to determine why such transparently incomplete sequences can nevertheless function as a constituent.

Confi rming this analysis, the flexibility within limits of dative-marked NPs is also expected. In particular we expect that, in circumstances where a pairwise interpretation of two left-peripheral NPs is debarred, as in (14), where the embedded predicate is mekessta 'eat', the only possible interpretation of the dative Jina-ekey 'to Jina' is as part of the matrix predicate-argument structure:

(14) Sakwa-rul Jina-ekey Mina-ka Yuna-ka mekessta-ko apple $_{A C C}$ Jina $_{D A T}$ Mina $_{N O M}$ Yuna $_{N O M}$ ate $_{C O M P}$ kiekhayssta-ko malhayssta remembered $\mathrm{COMP}_{O}$ said

'Mina said to Jina she remembered Yuna ate the apple.'

Moreover, should the relative order of mekessta 'remember' and malhayssta 'say' be reversed, with the matrix verb now debarring any matrix construal of the dative, we anticipate, correctly, that the sentence is ungrammatical: 


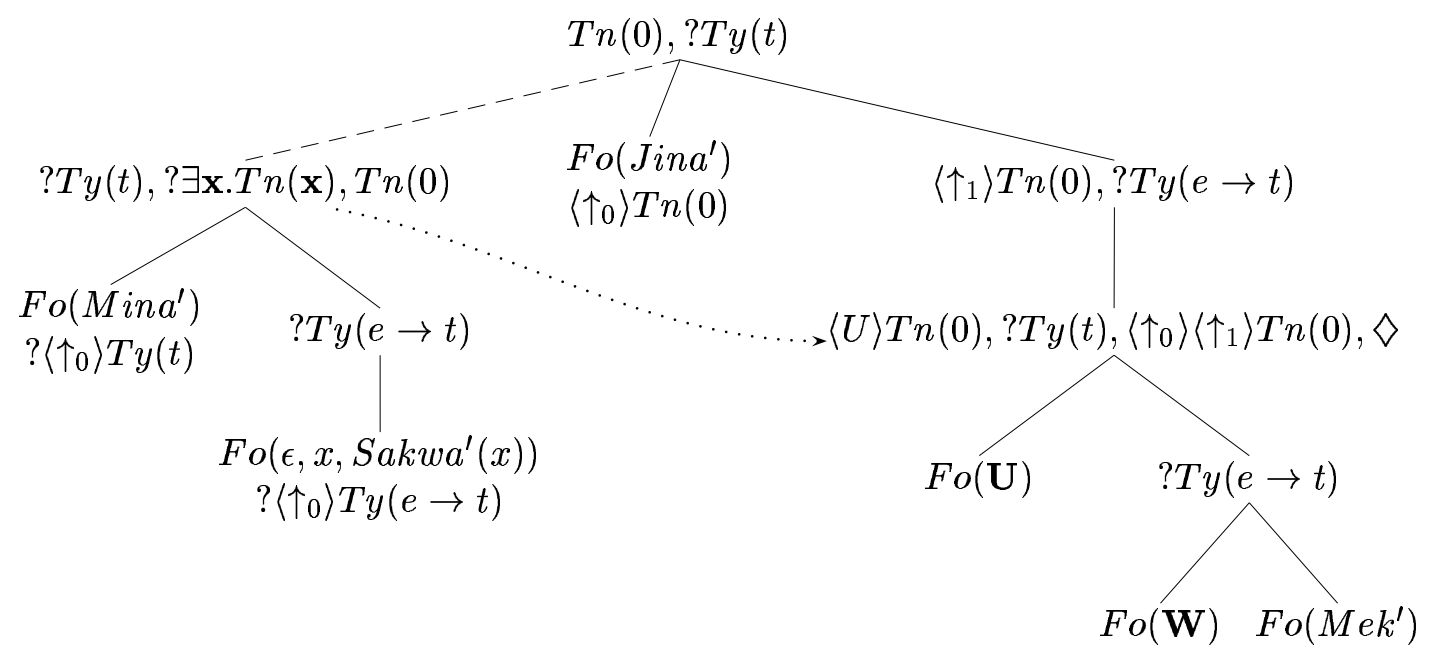

Figure 10: Left dislocation of sakwa-rul Mina-ka

(15) * Sakwa-rul Jina-ekey Mina-ka Yuna-ka mekessta-ko malhayssta-ko apple $_{A C C}$ Jina $_{D A T}$ Mina $_{N O M}$ Yuna $_{N O M}$ ate $_{C O M P} \quad \operatorname{said}_{C O M P}$ kiekhayssta remembered

* 'Mina remembered to Jina she said Yuna ate the apple.'

This result confi rms, in addition, the locality of the two long-distance scrambled NPs relative to each other, as there is no possibility of interpreting sakwa-rul relative to the most embedded predicate, and Jina-ekey relative to the intermediate predicate.

\section{At the Right Periphery}

In turning to the right periphery, the various constructs we have set up in analysing left-periphery effects come into their own, with minor variations that we can anticipate in virtue of the asymmetry between constructional processes operating at the closing stages of the interpretation process rather than as an opening sequence of actions. In particular, we shall use the building of linked structures, the building of unfi xed nodes, and variation between pronouns as to whether or not they decorate a terminal node in the tree under construction.

\subsection{Building Linked Structures in the Closing Stages}

First, just as at the left periphery, we might expect that a right-occurring expression, placed outside some clausal sequence, can be interpreted by building a LINK transition, with a background-topic form of interpretation, and so 
it can. In all languages, it is possible to interpret an expression with a pronoun in canonical position, buttressing its interpretation by some end-placed expression, and with topic-marking languages, we duly expect end-placed topicmarked NPs to occur:

(16) lo conosco, Giovanni. him I know Giovanni

[Italian] 'I know him, Giovanni.'

(17) I think you should realise that it's an impossible topic, right dislocation.
Tutie
wa-ss-ta
Chris-nun
Eventually come $P A S T, D E C$ Chris $T O P I C$
'Eventually he came, Chris.'

[Korean]

We refer to this form of backgrounding as Recapitulation and analyse it as shown in the schematic transition shown in Figure 11. Though this rule has to be explicitly defi ned, it is the mirror image of the early topic adjunction rule, and no more than we would expect, given that there is no ordering on the tree as to which of two linked trees is built first. We can now see what sort of interpretation a string whose structure is built up by this strategy is bound to have. Given that the pronoun in canonical position is construed as decorating a fi xed node (in the clitic case, initially unfi xed but immediately enriched to become fi xed), it will, unless expletive, have to be interpreted as indexical, from the larger context. But this means that in order to justify a LINK transition, the move to the linked structure will impose a requirement to identify the term decorating that linked structure in such a way as to yield a term identical to that which is interpreted from the pronoun. It can therefore only be interpreted as buttressing the already indexically fi xed construal of the pronoun: hence its reported background-topic effect. ${ }^{23} 24$

\subsection{Building Unfixed Nodes in the Closing Stages}

Secondly, we expect there to be instances of $*$ Adjunction, though, as we now see, this goes hand in hand with the characterisation of some pronouns as not decorating a terminal node in the resulting structure. The concept of defining some pronouns as losing their terminal node restriction provides an immediate

\footnotetext{
${ }^{23}$ The naturalness of this account is in marked contrast to that of Cecchetto (1999), who comments that such data are problematic for his account, but can safely be left on one side, since they are problematic for all accounts currently available. See also Herring 1994, whose informal account of backgrounding effects in Tamil this analysis matches.

${ }^{24}$ The use of $\uparrow_{*}$, without angled brackets, indicates that the formula holds at a fi xed node.
} 


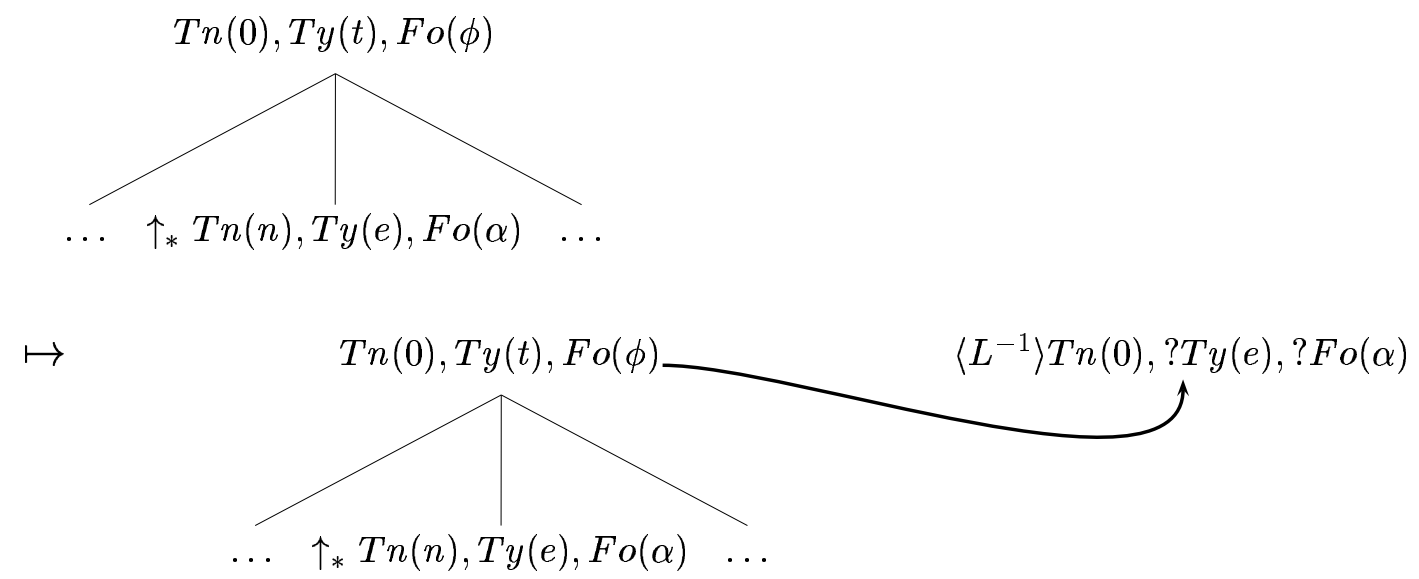

Figure 11: Licensing Linked Structures at the Right Periphery

explanation of expletive pronouns, the other major property of the computational system of natural language: ${ }^{25}$

(19) It's possible that I am wrong.

As we have already seen in developing the left periphery effects, some pronouns, while remaining expressions with full anaphoric potential, may lose one essential property of being regular lexical expressions in that they lose a terminal-node restriction; and this is an attendant and expected property of all argument nodes projected by a verb with pro-drop properties. This property is all we need to characterise expletive pronouns. With such an account, a derivation will be licensed in which the expletive projects a type value and incomplete formula value, a meta-variable like any other anaphoric expression, but one that, in failing to be assigned a contextually provided value, may have that value established later by the subsequent development of structure. Indeed such a process is essential if a formula value is to be provided, for without it the top node's requirement could not be met, and there would be no successful completion of the interpretation process.

The effect is as displayed in Figure 12. In English, this sub-use of the pronoun it requires specifi c itemisation, as the pronoun of type $e$ is not associated with any such expletive effect. The action which introduces the node allowing late development of the tree is an atrophied variant of *Adjunction, which we refer to as Late *Adjunction, and which is all we would expect once the entire structure has been constructed. The reason for this is two fold. First, the

\footnotetext{
${ }^{25}$ See Cann et al. 2004 for earlier versions of the ideas set out here. We are grateful to Lutz Marten, Masayuki Otsuka and David Swinburne for their contribution to the development of these concepts.
} 


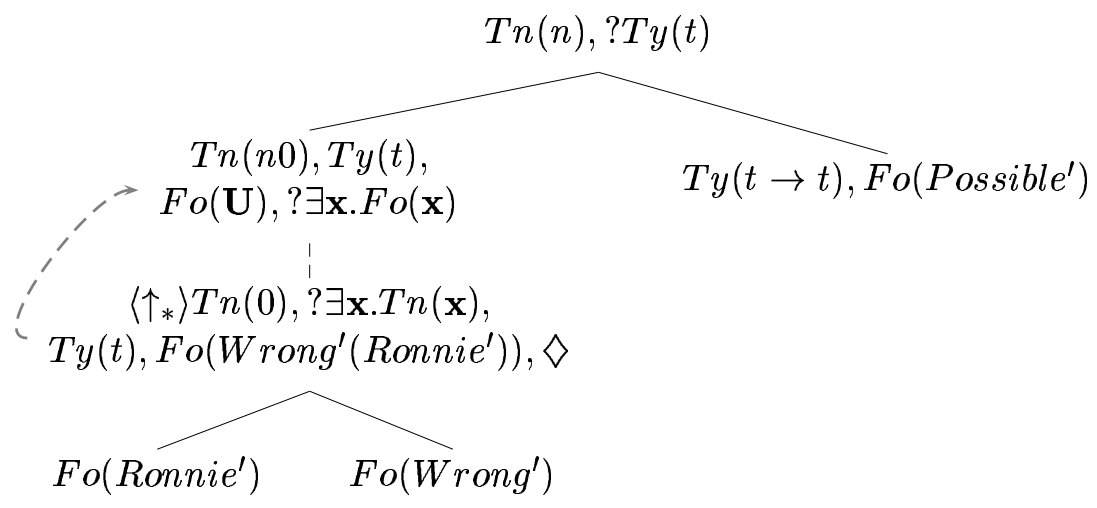

Figure 12: Parsing It is possible that I am wrong

process is one of building an unfi xed node of the same type as its dominating node. Such a process is a subpart of the steps involved in introducing an unfi xed node at the left periphery and progressively evaluating whether it can be unifi ed with a fi xed node through a tree. This proceeds step by step, node by node, as the tree is progressively constructed, so that at the point of unifi cation, the properties of the unfi xed and fi xed node are considered together. It is this confi guration which is directly constructed in Late*Adjunction. Secondly, in the case of expletives, with the pointer back at the subject node, the tree under development will be complete, apart from this late step of development. This is because in order for the pointer to be moved back to the subject node, the predicate must have been fully developed and compiled with type requirement and formula value fully specifi ed, for this is a necessary prerequisite for movement back up the tree from daughter to mother. It is thus only in seeking to compile a formula value at the top node that the outstanding requirement at the argument daughter emerges as a block on any such top node decoration. Accordingly, the pointer will return from the mother node to that node, licensing the introduction of a node of the very same type which, once developed, can unify with that subject node to satisfy whatever outstanding requirements it has. Hence the only possible application of *Adjunction at this late stage is the introduction of an unfi xed node of the same type, exactly preparatory for a step unifying the two nodes.

The bonus of this style of explanation is that it yields the Right Roof Constraint as an immediate consequence. Progressive decoration of nonterminal nodes up the tree is only possible if all requirements on pairs of daughter nodes for each mother are satisfi ed: the successful decoration of the mother node depends on this. So though the pointer may move away from some daughter node through the use of such devices as expletive pronouns, the compilation of properties at its mother node will need all requirements satisfi ed. This yields the 
Right Roof Constraint immediately. We expect that extraposition effects will be essentially local, and moreover end-placed in some clausal sequence. ${ }^{26}$ And so it is that from an embedded sentential subject, as in (20), it is impossible to have a place-holder in that subject position, and its associated clause removed to the right periphery of the matrix predicate, as in (21):

(20) That it is certain that I am wrong is unfortunate.

(21) *That it is certain is unfortunate that I am wrong.

In order for (21) to be wellformed, it would have to be possible to leave the construction of that embedded subject structure altogether, move the pointer from that structure to develop the matrix predicate, and then move back into the embedded subject at some late stage to complete its requirements. Given this restriction on pointer movement, that early movement of the pointer out of the embedded structure is impossible.

This account of expletive pronouns imposes no restriction that it is only lexically realised pronouns that might lack such a terminal node restriction. To the contrary, we expect that in pro-drop languages, no such expletive will be necessary, given the lack of bottom restriction on argument nodes decorated by the verb. The particular provision of a type specifi cation and meta-variable allows the node to be interpreted by either substitution of some contextually provided value or by late provision of a term, as we would expect:

(22) Compró un coche Maria

[Spanish]

bought a car Maria

'She bought a car, Maria.'

(23) Tutie wa-ss-ta Chris-ka

[Korean]

Eventually came Chris $_{N O M}$

'Eventually he came, Chris.'

In Korean, we also fi nd the same locality constraint operative. Unlike leftperiphery effects, such late adjunction is restricted to matrix arguments - the Right Roof Constraint again in evidence:

(24) Mina-ka Jina-ka sakwa-rul cwuessta-ko malhayssta Yuna-ekey Mina $_{N O M}$ Jina $_{N O M}$ apple $_{A C C}$ gave $C O M P$ said Yuna $D A T$

'Mina said to Yuna that Jina gave an apple.'

$\neq$ 'Mina said that Jina gave an apple to Yuna.'

(25) * Mina-ka Jina-ka sakwa-rul cwuessta-ko kiekhayssta Yuna-ekey Mina $_{N O M}$ Jina $_{N O M}$ apple $_{A C C}$ gave $_{C O M P}$ remembered Yuna ${ }_{D A T}$ * 'Mina remembered to Yuna that Jina gave an apple.'

\footnotetext{
${ }^{26}$ In so far as this holds for expletives in the predicate, the same principle will apply.
} 
The reason is, as before, that to compile an interpretation for the matrix predicate, all more subordinate structure must be fully decorated. Argument nodes of that matrix predicate may be returned to for further development, exactly analogous to subject pro-drop effects in the Romance languages, and as though an expletive pronoun were present; but subordinate argument nodes are not accessible.

There is one further prediction, contrary to left-periphery effects, given the dynamics of the update process. Though there only one unfi xed node of a type is licensed at a time, this injunction holds only as long as that node is unfi xed. Once a node introduced by *Adjunction has had its position in the tree resolved, application of Late*Adjunction will be possible. We therefore correctly predict the co-presence of an expression at the left periphery and an expression at the right periphery, despite the restriction:

$\begin{array}{lllll}\text { sakwa-rul Mina-ka Jina-ka cwuessta-ko malhayssta } & \text { Yuna-ekey } \\ \text { apple }_{A C C} \text { Mina }_{N O M} \mathrm{Jina}_{N O M} & \text { gave }_{C O M P} & \text { said } & \text { Yuna }_{D A T} \\ \text { 'An apple, Mina said to Yuna that Jina gave.' } & & \end{array}$

In both instances, use of such peripherally placed expressions is contrastive, a point to which we shall return.

With the two processes of either extending the tree or building a paired linked tree available at the right periphery, we expect, as at the left periphery, a range of mixed effects. In Korean, the combination of these strategies, with the potential provided by choices between no pronoun, case-marked pronouns, and topic-marked pronouns, licenses a rich array of effects. There can be nonsuffi xed use of names, which arguably matches their introduction into the tree following a step of Late*Adjunction:
Tutie
$w a-s s-t a$
Chris
Eventually come $P A S T, D E C$ Chris
'Eventually he came, Chris.'

There are also both case-marked and topic-marked end-placed names, to be characterised by Late*Adjunction and a LINK transition, respectively:
(28) Tutie
$w a-s s-t a$
Chris-ka/-nun
Eventually come $P A S T, D E C$ Chris ${ }_{N O M / T O P I C}$
'Eventually he came, Chris.'

\section{Topic and Focus as Consequences of Tree Growth}

Throughout the paper so far we have been manipulating analyses involving linked structures and unfi xed nodes without any association with particular concepts of topic or focus. With the overall perspective provided by left and right 
periphery effects, we can now get a sense of the extent to which the structural account provided matches these informal notions. Some of these will require setting against a dialogue background to receive a full explanation; but, nevertheless, it is of interest to see to what extent these relatively simple formal tools correspond with concepts familiar from the extensive topic and focus literature.

From the perspective of this framework, given that all parsing takes place in a context, we take the context to be some (minimal) sequence of partial trees immediately available to the parser during the parse process. What this suggests is that the topic is simply some (partial) tree which constitutes the point of departure. In dialogue, the speaker may simply take such immediate context as the starting point, but is also able to construct a point of departure, and in this lies the function of building a linked structure at the outset of an utterance. Such initially placed expressions may serve to create the relationship to the larger context (background topic), or they may constitute a departure from it (contrastive topic). The linked tree, created as the construal of the topic expression, is nothing more than a minimal context, relative to which the subsequent interpretive process takes place. This is most obviously displayed as a possible function in topic-marking languages, in which topic-marked expressions have two uses, either as background or as contrastive topic. Contrastive topic effects may also be conveyed by use of a topic-marked expression in the latter stages of an utterance:

\section{Wa-ss-ta Jina-nun came Jina TOPIC \\ 'She came, Jina.' (contrastive)}

In the decision to interpret some expression as projecting a separate structure to be necessarily construed as identical with some term in the propositional structure already constructed, rather than with the more general context, the expression used indicates a departure from what is provided by that more general context.

The other device, focus, which has to be conveyed within the time-linear dynamics of an utterance, is the ability to separate off some expression from the remainder, not because it is the context relative to which the remainder is to be construed, but, to the contrary, because it is to be isolated as the specifi c form of update relative to some proposition to be taken as context. And in this lies the function of building unfi xed nodes by regular application of *Adjunction, by defi nition a process of building a node, then a propositional frame, and at some relatively late stage of the construction process unifying the two. However, such focus effects, as we might now call them, can be constructed either, by using *Adjunction or by using the context directly, as with topic effects. And in answers to questions, the canonical focus structures, the question provides the context, relative to which the answer provides the update; and the relationship 
may be one of directly taking the very structure provided by the context and updating it to provide a new structure:

(30) Who did John annoy? His mother.

Broadly, focus is some update structure which is provided for a given propositional structure, and in this case too, such structure may be independently provided in context or may be constructed as part of the interpretation process, immediately prior to the point of update which identifi es the focussed structure. These concepts express intuitions that are similar to the fi le metaphor of Vallduvi (1991), Erteschik-Shir (1997) and others; but in the Dynamic Syntax framework, the very dynamics which constitutes the grammar formalism itself provides the basis of what is needed to explain these effects. So though the matter requires exploration in detail (see Kiaer, in preparation), topic and focus effects promise to be epiphenomena, emerging from the general form and growth of natural language structure - the concepts of linked structures and unfi xed nodes, constructed both at early and at late stages of the utterance interpretation process, reflecting informal concepts of topic and focus without having to articulate these as primitive terms of the explanation.

\section{Summary}

In this paper, we have set out two basic concepts of tree growth, using these to sketch an analysis of left and right periphery effects that extends to verb-fi nal languages as a natural part of the overall explanation. Notable new results are the accounts of multiple scrambling at the left periphery and the Right Roof Constraint at the right periphery, both of which are problematic for many other frameworks. This asymmetry between left and right periphery effects is a notable bonus over other frameworks, for which symmetry is expected and asymmetries require special stipulation. Furthermore, concepts of topic and focus promise to emerge as a consequence of the concepts defi ned. We conclude that properties of natural language syntax are founded directly in the dynamics of the parsing process.

\section{References}

Anagnostopoulou, Eleana, Henk van Riemsdijk, Franz Zwarts, eds., 1997. Leftward Movement. John Benjamins, Amsterdam.

Belletti, Andrea. 1999. Inversion as Focalization and Related Questions. Catalan Working Papers in Linguistics 7: 9-45.

Blackburn, Patrick and Meyer-Viol, Wilfried. 1994. Linguistics, logic, and fi nite trees. Bulletin of the Interest Group of Pure and Applied Logics 2: 2-39.

Boeckx, Cedric. 2003. Islands and Chains. Benjamins, Amsterdam.

Büring, Daniel. 1997. Meaning of Topic and Focus: 59th Street Bridge Accent. Routledge, 
London.

Cann, Ronnie et al. 2004. On the Left and on the Right. In Adger, David et al. eds., Peripheries. Kluwer, Dordrecht, pp.19-47.

Cecchetto, Carlo. 1999. A Comparative Analysis of Left and Right dislocation in Romance. Studia Linguistica 53: 40-67.

Cinque, Guglielmo. 1990. Types of A-bar dependencies. MIT Press, Cambridge, MA.

Erteschik-Shir, Nomi. 1997. The Dynamics of Focus Structure. Cambridge University Press, Cambridge.

Herring, Susan. 1994. Afterthoughts, Antitopics, and Emphasis: the Syntactization of Postverbal Position in Tamil. In Butt, Miriam, Tracy H. King and Gillian Ramchand, eds., Theoretical Perspectives on Word Order in South Asian Languages, CSLI Stanford, pp. 119-152.

Hoffman, Beryl. 1995. Computational Analysis of the Syntax and Interpretation of 'Free' Word Order in Turkish. Ph.D. diss., University of Pennsylvania, Philadelphia.

Jang, Youngjun. 1998. Multiple Subject and Characterization. Discourse and Cognition 5.

Kayne, Richard. 1994. Antisymmmetry in Syntax. MIT Press, Cambridge, MA.

Kempson, Ruth, Meyer-Viol, Wilfried, and Gabbay, Dov. 2001. Dynamic Syntax: The Flow of Language Understanding. Basil Blackwell, Oxford.

Kempson, Ruth. 2003. Nonrestrictives and Growth of Logical Form. West Coast Conference in Formal Linguistics 22. Cascadilla Press, Somerville, pp. 110-114.

Kempson, Ruth and Meyer-Viol, Wilfried. 2004. Indefi nites and Scope Choice. In Marga Reimer and Anne Bezuidenhout, eds., Descriptions and Beyond. Oxford University Press, Oxford.

Kempson, Ruth; Cann, Ronnie and Kiaer, Jieun. 2004a. Topic, Focus, and the Structural Dynamics of language. Proceedings of GLOW 2003 Workshop on Topic and Focus (submitted).

Kempson, Ruth. 2004. Japanese Word Order: Structural Underspecifi cation and Growth of Information. Submitted to Journal of Applied Logic.

Kempson, Ruth; Cann, Ronnie and Marten, Lutz. 2004. The Dynamics of Language. Submitted to Elsevier.

Kitagawa, Yoshihita. 1986. Subjects in Japanese and English. Ph.D. diss., University of Massachusetts, Amherst.

Koizumi, Masatoshi. 2000. String Vacuous Overt Verb Raising. Journal of East Asian Languages 9: 227-285.

Nordlinger, Rachel. 1998. Constructive Case. CSLI, Stanford.

Rogers, James. 1995. Studies in the Logic of Trees with Applications to Grammar Formalisms. Ph.D. diss., University of Pennsylvania, Philadelphia.

Simpson, Andrew and Tanmoy Bhattacharya. 2003. Obligatory Overt Wh-Movement in a Wh-in-situ Language. Linguistic Inquiry 34(1): 127-142.

Steedman, Mark. 2000. The Syntactic Process. MIT Press, Cambridge, MA.

Takano, Yuji. 2002. Surprising Constituents. Journal of East Asian Languages 11: 243-301.

Vallduví, Enric. 1991. The Informational Component. Ph.D. diss., University of Pennsylvania, Philadelphia. 